\title{
SEMEADURA DO MILHO EM SISTEMA DE PLANTIO DIRETO SEM E COM MANEJO MECÂNICO DA MATÉRIA SECA
}

\author{
PEDRO H. WEIRICH NETO ${ }^{1}$, ALTAIR JUSTINO ${ }^{2}$, RODOLFO K. ANTUNES ${ }^{3}$, \\ ALLISON J. FORNARI ${ }^{4}$, LUIZ C. GARCIA ${ }^{5}$
}

\begin{abstract}
RESUMO: O objetivo deste trabalho foi verificar se a cultura do milho é influenciada pelo manejo mecânico da aveia-preta dessecada antes de sua semeadura, pela utilização de rolo destorroador. Os tratamentos consistiram na semeadura do milho sob a matéria seca de aveia-preta dessecada sem manejo mecânico e rolada. $\mathrm{O}$ experimento foi realizado em quatro propriedades, duas na safra de 2007/2008 e as outras duas na safra de 2008/2009. O delineamento experimental adotado foi em blocos ao acaso, com 11 repetições, cujas parcelas possuíam $80 \mathrm{~m}^{2}$ cada. Avaliaram-se a qualidade da semeadura e os componentes de rendimento. Conclui-se que o manejo mecânico da palha de aveia-preta antes da semeadura do milho pode elevar significativamente os espaçamentos falhos e reduzir significativamente os espaçamentos aceitáveis. Nas áreas experimentais, os tratamentos não afetaram os componentes de rendimento da cultura do milho, havendo apenas acréscimo no custo da produção.
\end{abstract}

PALAVRAS-CHAVE: aveia-preta, rolo destorroador, componentes de rendimento.

\section{NO TILL CORN SEEDING WITH AND WITHOUT MECHANICHAL MANAGEMENT OF DRY MATTER}

\begin{abstract}
The aim of this study was to determine whether the corn is influenced by the management of dry oat before sowing, by the use of roller-Loosening. The treatments consisted of sowing the corn in the oat dry matter without mechanical handling and rolled. The experiment was conducted in four properties, two in the 2007/2008 harvest, and two others in the 2008/2009 season. The experimental design was randomized blocks with 11 repetitions, which plots had $80 \mathrm{~m}^{2}$ each. It was evaluated the quality of sowing and yield components. It was concluded that in the four agricultural properties and two years mechanical handling of the oat straw before sowing the corn significantly increased the spacing flawed, significantly reduced the acceptable spacing and did not affect the corn yield, and only increased the cost of production.
\end{abstract}

KEYWORDS: oat, roller-Loosening, yields components.

\section{INTRODUÇÃO}

O rendimento de grãos da cultura depende de condições favoráveis de ambiente, genéticos e de manejo (MAGALHÃES \& DURÃES, 2008). Na cultura do milho, não há compensação da falta de plantas por perfilhamento ou produção de floradas. Sendo assim, a semeadura deve receber atenção especial, de forma a assegurar uma população com chances de alcançar maiores produtividade e rentabilidade (EMBRAPA, 2011).

As operações de manejo utilizadas na agricultura modificam algumas condições físicas do solo associadas à estrutura, como a disponibilidade de água, a aeração e a resistência ao crescimento das raízes, diretamente relacionadas ao crescimento das plantas e ao rendimento de grãos (NOVAIS \& MELLO, 2007). Solos manejados em semeadura direta sob a palha adquirem condições físicas

\footnotetext{
${ }^{1}$ Eng ${ }^{-}$Agrícola, Professor Doutor, Universidade Estadual de Ponta Grossa - PR.

${ }^{2}$ Eng ${ }^{0}$ Agrônomo, Professor Doutor, Universidade Estadual de Ponta Grossa - PR.

${ }^{3}$ Acadêmico de Agronomia da UEPG, Universidade Estadual de Ponta Grossa - PR.

${ }^{4}$ Eng ${ }^{0}$ Agrônomo, Mestrando em Agronomia, Universidade Estadual de Ponta Grossa - PR.

${ }^{5}$ Eng $^{\mathrm{o}}$ Agrônomo, Universidade Estadual de Ponta Grossa - PR.

Recebido pelo Conselho Editorial em: 2-8-2011

Aprovado pelo Conselho Editorial em: 10-2-2012
} 
diferentes daqueles solos submetidos ao preparo convencional (REINERT et al., 2008). A manutenção da cobertura vegetal sobre o solo representa diferenças fundamentais entre plantio direto e preparo convencional (FURLANI et al., 2007). Por apresentar elevada produção de massa seca (GARCIA et al., 2006), facilidade de aquisição de sementes e de implantação, rusticidade (ALVIM, 2006), rapidez de formação de cobertura (CARVALHO \& AMABILE, 2006), eficiente reciclagem de nutrientes (CRUSCIOL et al., 2008) e ciclo adequado, a aveia-preta é a espécie de cobertura de solo mais utilizada no Sul do Brasil, no período de inverno, antecedendo ao cultivo do milho semeado em sistema de semeadura direta (IAPAR, 2011).

A aveia-preta pode influenciar a produtividade do milho pela adubação do sistema (CAIRES, 2006), forma de dessecação (ROSOLEM et al., 2007), tipo de manejo mecânico utilizado (BALBINOT JÚNIOR et al., 2008), dificuldade de semeadura pelo volume de palha acumulado (SANTOS et al., 2010) e a germinação pela alelopatia (BUENO et al., 2007).

Avaliando a influência de seis manejos da aveia-preta (dessecação química, dessecação química seguida de rolagem com rolo-faca, rolagem seguida de dessecação química, rolagem, trituração e trituração seguida de dessecação química) para semeadura direta de milho, ARAÚJO \& RODRIGUES (2000) não identificaram incremento significativo na produtividade da cultura.

Estudando os efeitos do manejo mecânico da aveia-preta no milho em sucessão, ARGENTA et al. (2001) concluíram que a forma de manejo dos resíduos da aveia-preta (não rolada, rolada ou roçada) e do tipo de herbicida não seletivo (glifosate, glufosinate e paraquate), utilizado em sua dessecação, não afeta o rendimento de grãos de milho.

Segundo CORTEZ et al. (2009), o manejo da cultura - para fornecimento de palha para o sistema de semeadura direta - com herbicida, triturador e rolo-faca, não afetou a cobertura, o estande inicial, dias para emergência, estande final e produtividade da cultura do milho.

Na região dos Campos Gerais do Paraná, onde a semeadura direta de milho sob a palha de aveia-preta predomina, as propriedades dividem-se sobre a utilização ou não do manejo mecânico da aveia-preta. O manejo mecânico da aveia-preta dessecada mais utilizado na região é com o rolo destorroador. Conforme a FUNDAÇÃO ABC (2009), o custo do manejo mecânico da aveia-preta com rolo destorroador foi de $\mathrm{R} \$ 15,83$ por hectare. O preço de venda do milho, na mesma região e época, foi de $\mathrm{R} \$ 19,00$ a saca de $60 \mathrm{~kg}$ (AGROLINK, 2009).

A literatura consultada não traz informações sobre o manejo mecânico da aveia-preta dessecada com rolo destorroador, bem como seus benefícios para cultura subsequente. Assim, o objetivo deste experimento foi avaliar a influência do manejo mecânico da palha de aveia-preta com rolo destorroador, precedendo a implantação da cultura do milho.

\section{Descrição do assunto}

Condições experimentais

O experimento foi realizado em quatro propriedades, duas na safra de 2007/2008 e as outras duas na safra de 2008/2009. As propriedades estão situadas na região dos Campos Gerais, no Estado do Paraná, localizado nas coordenadas $25^{\circ} 16^{\prime \prime}$ de latitude sul e $50^{\circ} 16^{\prime \prime}$ de longitude oeste, clima $\mathrm{Cfb}$, em sistema de semeadura direto sob a palha. $\mathrm{O}$ regime pluviométrico dos dois anos agrícolas em que a cultura do milho foi conduzida está detalhado na Figura 1.

A propriedade "A" está localizada em Arapoti - PR, com 960 m de altitude e Latossolo Vermelho eutrófico. No dia 28 de setembro de 2007, distribuíram-se 75.000 sementes por hectare do híbrido $30 \mathrm{R} 50^{\circledR}$, com $6,8 \mathrm{t} \mathrm{ha}^{-1}$ de palha de aveia-preta. O trator era o CBT $8060-73,5 \mathrm{~kW}$ $(100 \mathrm{cv})$. A semeadora-adubadora foi a SSM 27, equipada com seis unidades de semeadura, espaçadas entre si em $0,80 \mathrm{~m}$, com sistema de disco perfurado horizontal, disco de corte da palhada liso, com 0,36 m de diâmetro, sulcadores de adubo do tipo "facão", com ponteiras de 0,025 m de largura, e ângulo de ataque de $20^{\circ}$ (guilhotina) e mecanismo de abertura do sulco da semente, com disco duplo desencontrado de $0,33 \mathrm{~m}$ de diâmetro. 


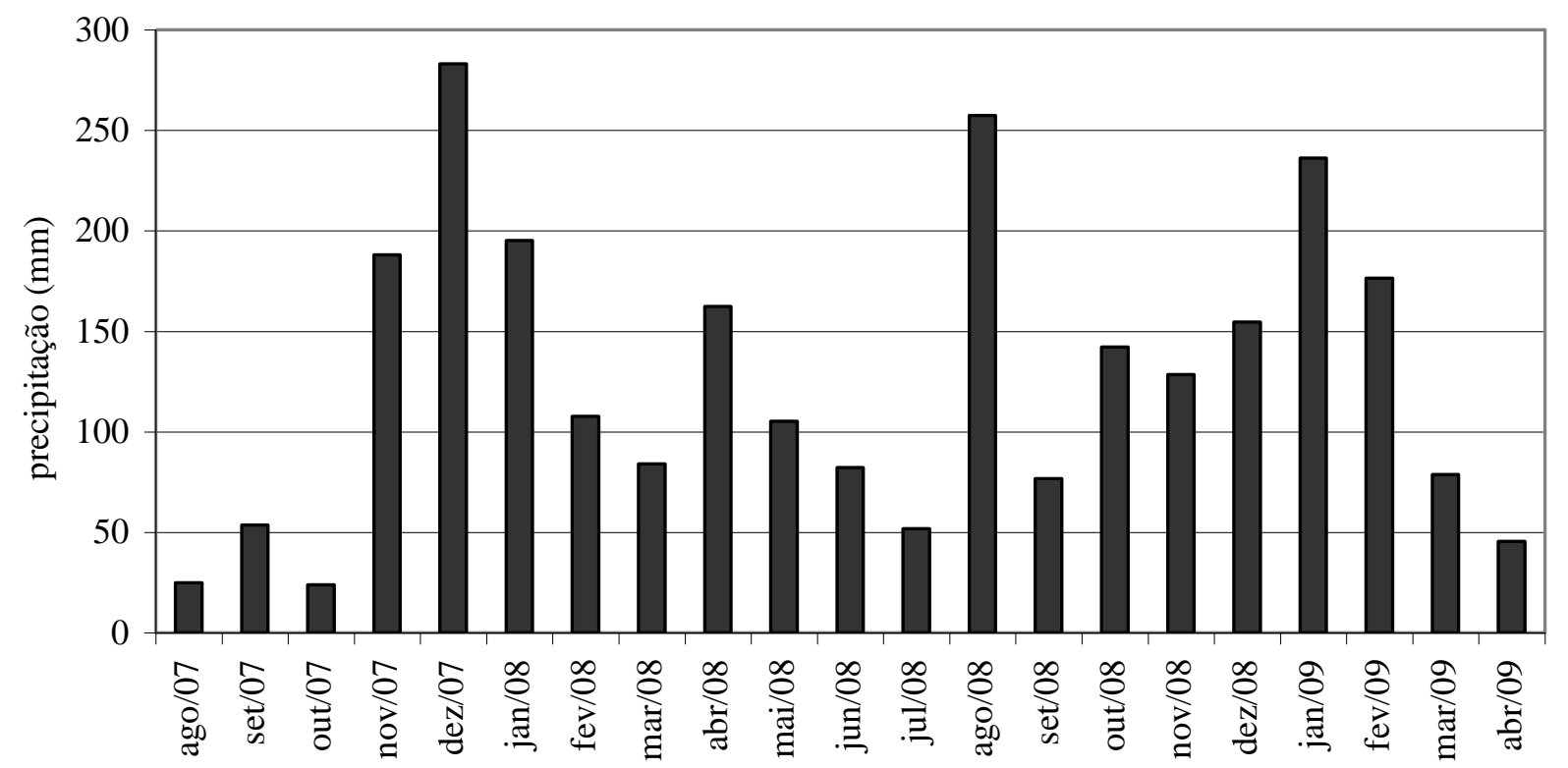

FIGURA 1. Pluviosidade na região dos Campos Gerais - PR, de agosto de 2007 a abril de 2009. Rainfall in the region of Campos Gerais - PR, from August 2007 to April 2009.

A propriedade "B" está localizada no município de Tibagi - PR, com $750 \mathrm{~m}$ de altitude e Latossolo Vermelho eutrófico. No dia 16 de outubro de 2007, distribuíram-se 72.000 sementes por hectare do híbrido $2 \mathrm{~B} 710^{\circledR}$, com $5,4 \mathrm{t} \mathrm{ha}^{-1}$ de palha de aveia-preta. O trator utilizado foi o John Deere 6600 - 88,2 kW (120 cv). A semeadora-adubadora empregada foi a pneumática SLC 913, equipada com sete unidades de semeadura, espaçadas entre si em $0,80 \mathrm{~m}$, mecanismo de abertura de sulco do adubo com disco simples, tubo condutor de adubo tipo eso (botinha), disco de corte da palhada com oito ondas - de $0,30 \mathrm{~m}$ - adaptado na frente do mecanismo de abertura do sulco da semente com disco duplo desencontrado de $0,33 \mathrm{~m}$ de diâmetro e fechamento com rodas duplo-anguladas em "V" de 0,30 m.

A propriedade "C" está localizada no município de Piraí do Sul, com $910 \mathrm{~m}$ de altitude e Latossolo Vermelho distrófico. No dia 21 de setembro de 2008, distribuíram-se 69.000 sementes por hectare do híbrido Maximus ${ }^{\circledR}$, com $4,9 \mathrm{t} \mathrm{ha}^{-1}$ de palha de aveia-preta. O trator utilizado foi o John Deere 7500 - 103 kW (140 cv). A semeadora-adubadora empregada era a pneumática SLC 913, com sete unidades de semeadura, espaçadas entre si em $0,80 \mathrm{~m}$, com disco de 30 orifícios, disco de corte liso de 0,36 m de diâmetro, sulcadores de adubo do tipo "facão", com ponteiras de $0,025 \mathrm{~m}$ de largura e ângulo de ataque de $20^{\circ}$ (guilhotina), mecanismo de abertura do sulco da semente com disco duplo desencontrado de $0,33 \mathrm{~m}$ de diâmetro e fechamento com rodas duploanguladas em "V" de $0,30 \mathrm{~m}$.

A propriedade "D" está localizada em Tibagi - PR, com 890 m de altitude e Latossolo Vermelho-Amarelo distrófico. No dia 17 de setembro de 2008, distribuíram-se 75.000 sementes por hectare do híbrido 30R50 ${ }^{\circledR}$, com 4,6 t ha ${ }^{-1}$ de palha de aveia-preta. O trator era o Massey Ferguson 292 - 77,2 kW (105 cv). A semeadora-adubadora foi a SSM 23, equipada com seis unidades de semeadura, espaçadas entre si em $0,80 \mathrm{~m}$, com disco perfurado horizontal de 28 orifícios, disco de corte liso de 0,36 $\mathrm{m}$ de diâmetro, sulcadores de adubo do tipo disco duplo desencontrado de 0,33 $\mathrm{m}$ de diâmetro, mecanismo de abertura do sulco da semente com disco duplo desencontrado de 0,33 m de diâmetro e fechamento com rodas duplo-anguladas em "V" de 0,30 m.

Em todas as propriedades, a aveia-preta foi dessecada com 2,0 $\mathrm{L} \mathrm{ha}^{-1}$ de glifosato, aos 40 dias, e rolada 20 dias antes da semeadura. Todas as semeadoras-adubadoras foram reguladas para que a semente fosse distribuída a $0,05 \mathrm{~m}$ de profundidade, com o fertilizante depositado a $0,05 \mathrm{~m}$, ao lado e abaixo da semente. Os depósitos de adubo e de semente foram abastecidos a $50 \%$ de sua 
capacidade. Todas as sementes de milho estavam acima de $95 \%$ de germinação e abaixo de $1 \%$ de impureza. O teor médio de água no solo, na camada de zero a $0,1 \mathrm{~m}$, esteve entre 250 e $300 \mathrm{~g}$ de água $\mathrm{kg}^{-1}$ de solo. $\mathrm{O}$ controle de plantas daninhas, pragas e doenças seguiram os padrões das fazendas. As colheitas, dos dois anos agrícolas, foram realizadas no mês de março.

O rolo destorroador de arrasto utilizado foi da WAIGA®. O implemento possuía seis seções. Cada seção tinha $2,6 \mathrm{~m}$ de largura e $600 \mathrm{~kg}$, totalizando $15,6 \mathrm{~m}$ e $3.706 \mathrm{~kg}$. A seção estava constituída de um chassi retangular ao qual era fixado um eixo sustentado por mancais. Cada eixo possuía 35 discos, sendo esses dispostos em sequência alternada de lisos e dentados (Figura 2).

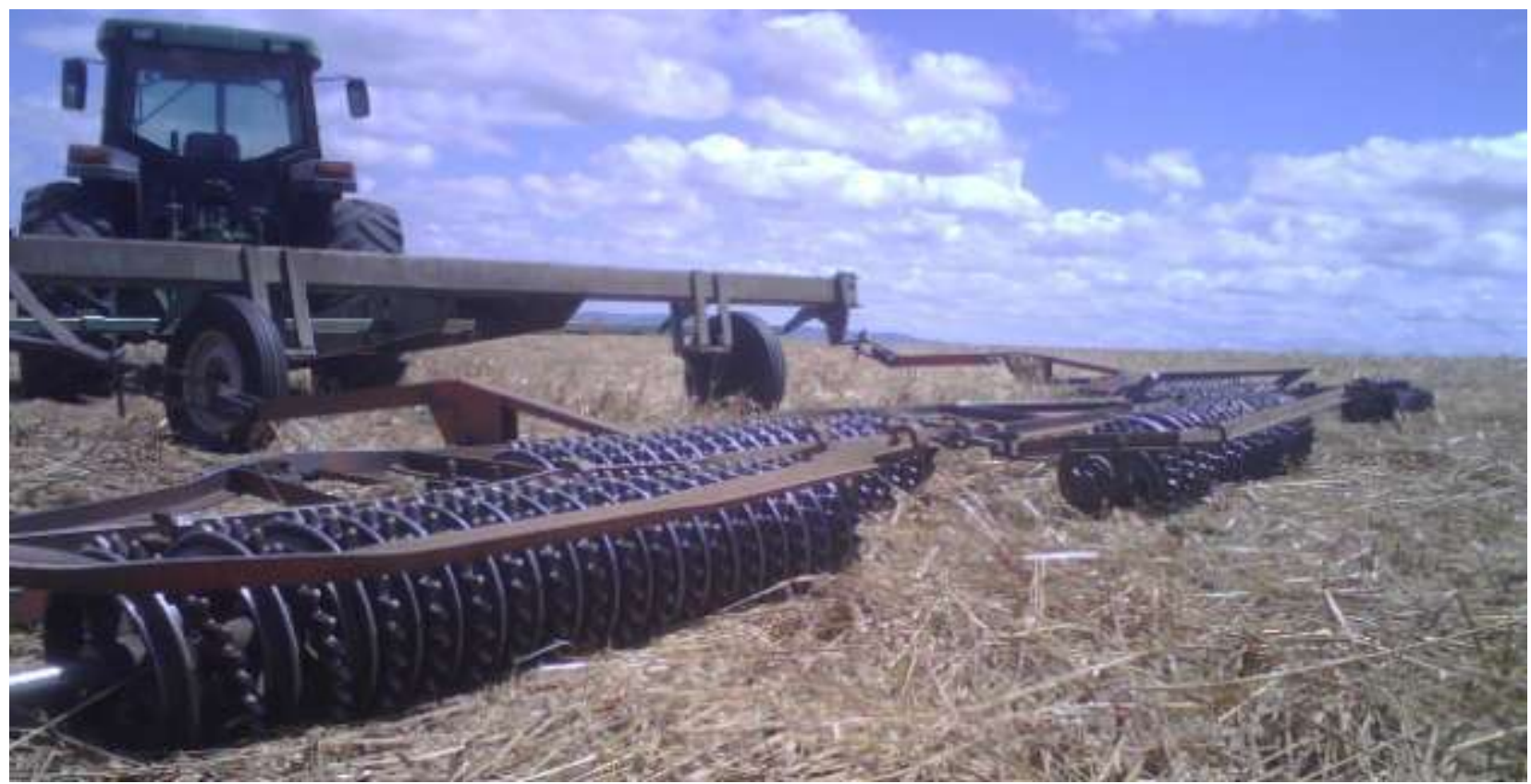

FIGURA 2. Rolo destorroador utilizado para rolagem de aveia-preta (Avena strigosa S.) manejada quimicamente para semeadura de milho em sistema de plantio direto, na região dos Campos Gerais - PR. A land roller used to roll oats (Avena strigosa S.) managed chemically for corn seeding in no-tillage in the region of Campos Gerais - PR.

Em cada propriedade, o delineamento experimental foi em blocos casualizados, com dois tratamentos, com ou sem a utilização do rolo destorroador, após manejo químico e 20 dias antes da semeadura do milho, em 11 repetições por tratamento. As parcelas tinham área útil de 16 x $5 \mathrm{~m}$ devido ao tamanho do rolo destorroador. O tamanho da amostra levou em consideração a estabilização da média e do desvio-padrão das variáveis analisadas, conforme método proposto por KRANZ (1988). Aplicou-se o teste de Hartley para a verificação da homocedasticidade das variâncias. As variáveis mensuradas foram submetidas ao teste $\mathrm{F}$ por haver apenas dois tratamentos.

As variáveis avaliadas foram: população inicial (com 20 dias após a emergência- DAE), espaçamentos falhos, espaçamentos múltiplos, espaçamentos aceitáveis, número de espigas por hectare (15 dias antes da colheita), grãos por espiga, massa de mil grãos, produtividade e viabilidade econômica da operação.

Os espaçamentos foram determinados com base no Projeto de Norma da ABNT (1996), que considera como aceitáveis todos os espaçamentos entre sementes de 0,5 a 1,5 vez o espaçamento médio. Os valores obtidos fora desse limite foram considerados como espaçamentos falhos (acima de 1,5 vez espaçamento médio) ou múltiplos (abaixo de 0,5 vez espaçamento médio).

A contagem do número de espigas por área, colheita, debulha, contagem de grãos por espiga e a massa de mil grãos foram realizadas manualmente. A determinação da massa de mil grãos e a produtividade deram-se com grãos sem impurezas e com o teor de água foi corrigido para $145 \mathrm{~g} \mathrm{~kg}$

bu. O teor de água foi determinado com o uso de um determinador de teor de água (G800 
Gehaka®). A massa de mil grãos foi definida por meio de uma balança digital Diamond ${ }^{\circledR}$, com acurácia de $0,1 \mathrm{~g}$ a $500 \mathrm{~g}$. A viabilidade econômica foi definida pela comparação do custo de operação pelo acréscimo na produção.

\section{Análise dos resultados}

A estabilização da média e do desvio-padrão de todas as variáveis analisadas (KRANZ, 1988) ficou em $15 \mathrm{~m}^{2}$ por parcela. O teste de Hartley apontou a homocedasticidade das variâncias para todas as variáveis estudadas. Portanto, não houve necessidade de transformação das médias para aplicação do teste F. Não houve diferenças significativas para os blocos em todas variáveis avaliadas, denotando a homogeneidade das condições experimentais.

Analisando a qualidade da semeadura, cuja importância foi denotada pela EMBRAPA (2011), verifica-se que o manejo mecânico da aveia-preta dessecada, com rolo destorroador, influenciou significativamente no estabelecimento da cultura do milho, em três das quatro propriedades da região dos Campos Gerais no Paraná, em dois anos agrícolas diferentes (Tabela 1). O manejo mecânico elevou significativamente os espaçamentos falhos e reduziu significativamente os espaçamentos aceitáveis, contrariando as conclusões de CORTEZ et al. (2009). Em nenhum dos casos em estudo, houve alteração da população inicial (Figura 3) e espaçamentos múltiplos. Assim, o manejo mecânico pode ter alterado a germinação pelo volume de palha acumulado e pela alelopatia, como alertaram SANTOS et al. (2010) e BUENO et al. (2007).

TABELA 1. Qualidade na semeadura da cultura do milho (Zea mays L.) implantada na região dos Campos Gerais - PR, em sistema de semeadura direta sob a palha de aveia-preta (Avena strigosa S.), sem e com a utilização do rolo destorroador, após o manejo químico, em quatro propriedades e dois anos agrícolas distintos. Quality of maize seeding (Zea mays L.) deployed in the region of Campos Gerais -PR, Brazil, in tillage over black oats (Avena strigosa $\mathrm{S}$.), with and without the use of land roller after chemical management, in four properties and two different crop years.

\begin{tabular}{ccccc}
\hline Tratamento & $\begin{array}{c}\text { Plântulas } \\
\text { (ha) }\end{array}$ & $\begin{array}{c}\text { Espaçamentos } \\
\text { Falhos (\%) }\end{array}$ & $\begin{array}{c}\text { Espaçamentos } \\
\text { Múltiplos (\%) }\end{array}$ & $\begin{array}{c}\text { Espaçamentos } \\
\text { Aceitáveis (\%) }\end{array}$ \\
\hline Propriedade A (híbrido 30R50 ${ }^{\circledR} /$ semeadora SSM 27 / safra de 2007-20008) \\
\hline Sem rolo destorroador & $71.850 \mathrm{a}^{\mathrm{l}}$ & $4,2 \mathrm{~b}$ & $2,8 \mathrm{a}$ & $93,1 \mathrm{a}$ \\
Com rolo destorroador & $70.725 \mathrm{a}$ & $5,7 \mathrm{a}$ & $3,1 \mathrm{a}$ & $91,2 \mathrm{~b}$ \\
C.V. (\%) & 4,2 & 26,7 & 19,3 & 1,6 \\
\hline Propriedade B (híbrido 2B710 & / semeadora SLC 913 / safra de 2007-2008) \\
\hline Sem rolo destorroador & $68.025 \mathrm{a}$ & $5,5 \mathrm{~b}$ & $2,1 \mathrm{a}$ & $92,4 \mathrm{a}$ \\
Com rolo destorroador & $65.425 \mathrm{a}$ & $9,6 \mathrm{a}$ & $2,5 \mathrm{a}$ & $87,9 \mathrm{~b}$ \\
C.V. (\%) & 6,3 & 32,4 & 29,7 & 3,2 \\
\hline \multicolumn{6}{c}{ Propriedade C (híbrido Maximus ${ }^{\circledR} /$ semeadora SLC 913 / safra de 2008-2009) } \\
\hline Sem rolo destorroador & $66.696 \mathrm{a}$ & $3,6 \mathrm{a}$ & $2,6 \mathrm{a}$ & $93,8 \mathrm{a}$ \\
Com rolo destorroador & $66.429 \mathrm{a}$ & $3,9 \mathrm{a}$ & $2,7 \mathrm{a}$ & $93,4 \mathrm{a}$ \\
C.V. (\%) & 3,2 & 39,9 & 26,5 & 1,2 \\
\hline \multicolumn{6}{c}{ Propriedade D (híbrido 30R50 / semeadora SSM 23 / safra de 2008-2009) } \\
\hline Sem rolo destorroador & $71.078 \mathrm{a}$ & $4,6 \mathrm{~b}$ & $2,4 \mathrm{a}$ & $93,0 \mathrm{a}$ \\
Com rolo destorroador & $70.030 \mathrm{a}$ & $6,5 \mathrm{a}$ & $2,8 \mathrm{a}$ & $90,7 \mathrm{~b}$ \\
C.V. (\%) & 2,4 & 32,9 & 31,9 & 2,1 \\
\hline
\end{tabular}

1 - Médias seguidas de mesma letra não diferem significativamente, pelo teste $\mathrm{F}(\mathrm{P}>0,05)$.

A interação ambiente e manejo, mencionada por MAGALHÃES \& DURÃES (2008), pode ser analisada neste experimento. Na Figura 1, observa-se que, nos anos agrícolas em que o experimento foi instalado, houve déficit hídrico em 2007 e excesso de chuvas em 2008. Contudo, os resultados foram similares, denotando a importância da variável estudada em detrimento da pluviosidade. 


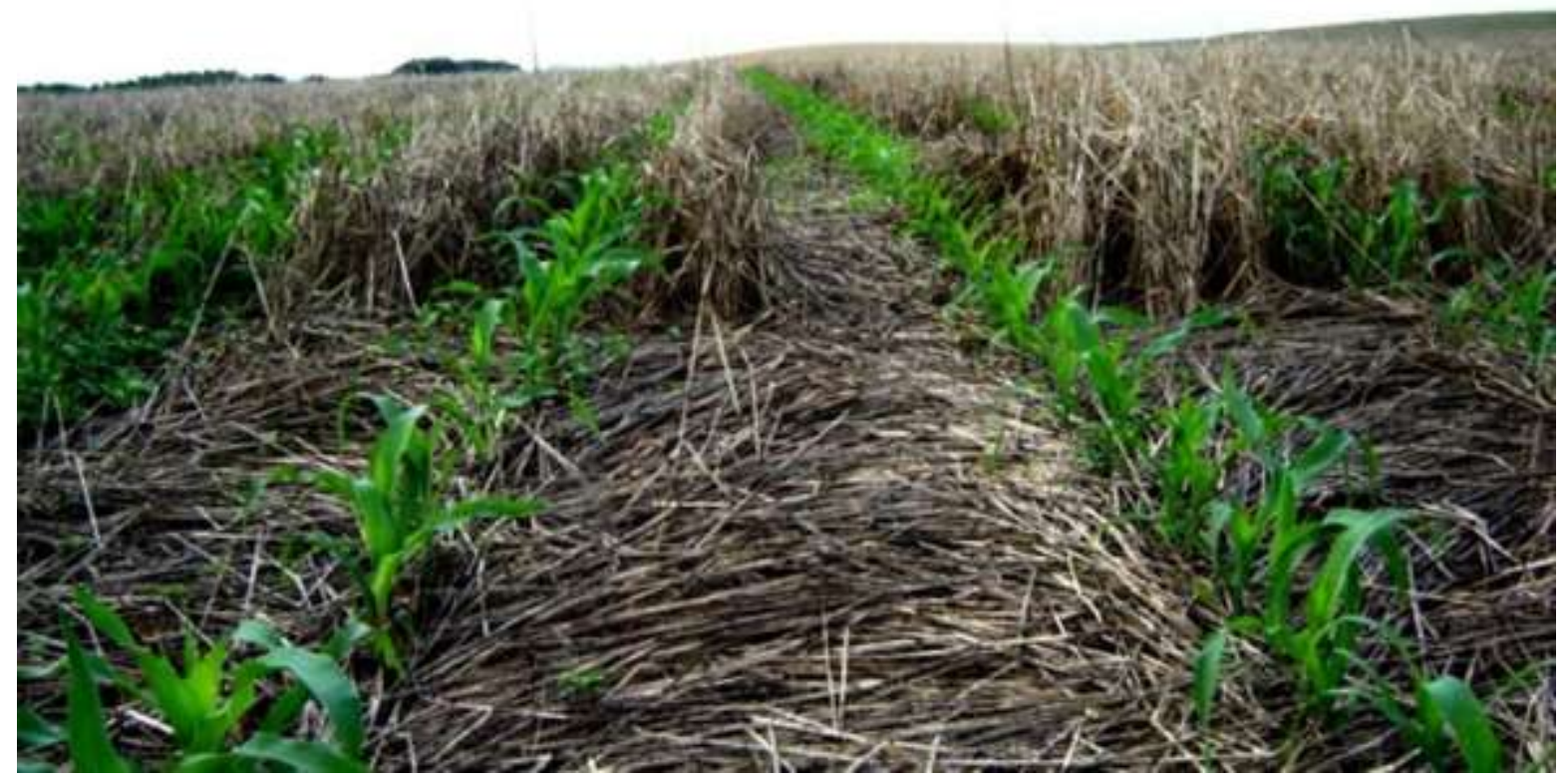

FIGURA 3. Cultura do milho (Zea mays L.) implantada na região dos Campos Gerais - PR em sistema de semeadura direta sob a palha de aveia-preta (Avena strigosa S.), sem e com a utilização do rolo destorroador após o manejo químico. Maize (Zea mays L.) deployed in the region of Campos Gerais - PR, Brazil, in tillage under black oats (Avena strigosa $\mathrm{S}$.), with and without the use of land roller after herbicide.

Contrariando as conclusões de BALBINOT JÚNIOR et al. (2008), nas condições experimentais, os componentes de rendimento da cultura do milho não foram influenciados significativamente pelo manejo mecânico da cultura antecessora (Tabela 2).

TABELA 2. Componentes de rendimento da cultura do milho (Zea mays L.) implantada na região dos Campos Gerais - PR, em sistema de semeadura direta sob a palha de aveia-preta (Avena strigosa S.), sem e com a utilização do rolo-destorroador após o manejo químico, em quatro propriedades e dois anos agrícolas distintos. Yield components of maize (Zea mays L.) deployed in the region of Campos Gerais - PR, Brazil, in tillage under black oats (Avena strigosa S.), with and without the use of land roller after chemical management, in four properties and two different crop years.

\begin{tabular}{ccccc}
\hline Tratamento & $\begin{array}{c}\text { Espigas } \\
\text { (ha) }\end{array}$ & Grãos por Espiga & $\begin{array}{c}\text { Massa de Mil } \\
\text { Grãos (g) }\end{array}$ & $\begin{array}{c}\text { Produtividade } \\
\left(\mathrm{kg} \mathrm{ha}^{-1}\right)\end{array}$ \\
\hline Propriedade A (híbrido 30R50 / semeadora SSM 27 / safra de 2007-2008) & \\
\hline Sem rolo destorroador & $70.775^{1}$ & 524 & 363 & 13.342 \\
Com rolo destorroador & 70.025 & 530 & 366 & 13.426 \\
C.V. (\%) & 2,0 & 10,8 & 12,1 & 4,7 \\
\hline Propriedade B (híbrido 2B710 / semeadora SLC 913 / safra de 2007-2008) & \\
\hline Sem rolo destorroador & 60.600 & 607 & 295 & 10.810 \\
Com rolo destorroador & 60.075 & 606 & 294 & 10.693 \\
C.V. (\%) & 5,9 & 11,0 & 4,1 & 9,0 \\
\hline Propriedade C (híbrido Maximus / semeadora SLC 913 / safra de 2008-2009) \\
\hline Sem rolo destorroador & 65.328 & 466 & 328 & 9.985 \\
Com rolo destorroador & 65.034 & 459 & 336 & 10.030 \\
C.V. (\%) & 3,5 & 6,3 & 5,1 & 7,9 \\
\hline Propriedade D (híbrido 30R50 / semeadora SSM 23 / safra de 2008-2009) \\
\hline Sem rolo destorroador & 66.250 & 469 & 260 & 8.073 \\
Com rolo destorroador & 66.094 & 466 & 262 & 8.062 \\
C.V. $(\%)$ & 4,8 & 8,3 & 6,6 & 5,4 \\
\hline
\end{tabular}

1 - Teste $\mathrm{F}$ não significativo para todas as variáveis analisadas $(\mathrm{P}>0,05)$. 
Os resultados corroboram as afirmações de ARAÚJO \& RODRIGUES (2000) e ARGENTA et al. (2001), de que a forma de manejo dos resíduos da aveia-preta não afeta o rendimento de grãos de milho. A análise dos dados confirma também as declarações de CORTEZ et al. (2009) quanto ao manejo da cultura para fornecimento de matéria orgânica à lavoura do milho.

Conforme a FUNDAÇÃO ABC (2009), o custo do manejo mecânico da aveia-preta com rolo destorroador, na região dos Campos Gerais, era de $\mathrm{R} \$ 15,83$ por hectare. O preço de venda do milho, na mesma região e época, foi de $\mathrm{R} \$ 19,00$ a saca de $60 \mathrm{~kg}$ (AGROLINK, 2009). Assim, o custo da operação seria de 0,83 sacos por hectare.

Houve um acréscimo no custo de produção sem elevação de produtividade, tornando a operação inviável. Como a utilização do rolo destorroador para manejar a aveia-preta dessecada é prática corrente na região dos Campos Gerais, se a propriedade "A" adotasse tal procedimento em seus 1.050 ha de milho, gastaria, desnecessariamente, $\mathrm{R} \$ 16.621,50$. Da mesma maneira, as propriedades “B", "C" e "D" elevariam seus custos em $\mathrm{R} \$ 42.741,00, \mathrm{R} \$ 31.660,00$ e $\mathrm{R} \$$ 9.213,06, respectivamente.

\section{CONCLUSÕES}

Em três, das quatro propriedades estudadas, o manejo mecânico da palha de aveia-preta antes da semeadura do milho elevou significativamente os espaçamentos falhos e reduziu significativamente os espaçamentos aceitáveis.

Os componentes de rendimento da cultura do milho não foram afetados pelo manejo mecânico da aveia-preta, havendo apenas acréscimo no custo da produção. Portanto, a operação é dispensável.

\section{REFERÊNCIAS}

ABNT. ASSOCIAÇÃO BRASILEIRA DE NORMAS TÉCNICAS. Projeto de norma 04:015.06004/1995. Semeadora de precisão: ensaio de laboratório/método de ensaio. São Paulo: ABNT, 1996. $21 \mathrm{p}$.

AGROLINK. Cotações do milho. Disponível em:<http://www.agrolink.com.br/cotacoes/ graos/ milho>. Acesso em: 18 abr. 2009.

ALVIM, J.M. Aveia e azevém: forrageiras alternativas para o período de seca. Brasília: EMBRAPA, 2006. 2 p.

ARAÚJO, A.G.; RODRIGUES, B. Manejo mecânico e químico da aveia-preta e sua influência sobre a taxa de decomposição e o controle de plantas daninhas em semeadura direta de milho. Planta Daninha, Viçosa-MG, v.36, n.6, p.151-160, 2000.

ARGENTA, G.; SILVA, P.R.F.; FLECK, N.G.; BORTOLINI, C.G.; NEVES, R.; AGOSTINETTO, D. Efeitos do manejo mecânico e químico da aveia-preta no milho em sucessão e no controle do capim-papuã. Pesquisa Agropecuária Brasileira, Brasília, v.36, n.6, p.851-860, 2001.

BALBINOT JÚNIOR, A.A.; MORAES, A.; PELISSARI, A.; DIECKOW, J.; VEIGA, M. Formas de uso do solo no inverno e sua relação com a infestação de plantas daninhas em milho (Zea mays) cultivado em sucessão. Planta Daninha, Viçosa-MG, v.26, n.3, p.569-576, 2008.

BUENO, J.; AMIAMA, C.; HERNANZ, J. L. No-tillage drilling of Italian ryegrass (Lolium multiflorum L.): crop residue effects, yields and economic benefits, Soil and Tillage Research, v.95, n. 1-2, p.61-68, 2007.

CAIRES, E.F.; GARBUIO, F.J.; ALLEONI, L.R.F.; CAMBRI, M.A. Calagem superficial e cobertura de aveia-preta antecedendo os cultivos de milho e soja em sistema de plantio direto. Revista Brasileira de Ciência do Solo, Viçosa-MG, v.30, p.87-98, 2006. 
CARVALHO, A.M.; AMABILE, R.F. Cerrado: adubação verde. Planaltina: Embrapa Cerrados, 2006. p.25-30.

CORTEZ, J.W.; FURLANI, C.E.A.; VIGNA, G.P.; BORSATTO, E.A.; SILVA, R.P. Desempenho do trator agrícola no manejo da cultura de cobertura e pressão de inflação do pneu da semeadora. Engenharia Agrícola, Jaboticabal, v.29, n.1, p.72-80, 2009.

CRUSCIOL, C.A.C.; MORO, E.; LIMA. E. do V.; ANDREOTTI, M. Taxa de decomposição e de liberação de macronutruientes da palhada de aveia-preta em plantio direto. Bragantia, Campinas, v.67, n.2, p.481-489, 2008.

EMBRAPA. Sistema de produção do milho, 2011. Disponível em:

<http://www.cnpms.embrapa.br/publicacoes/milho_6_ed/plantio.htm>. Acesso em: 29 mar. 2011.

FUNDAÇÃO ABC. Custo de mecanização agrícola. Disponível em: <http://www.fhonline.com.br/ suporte/customecanizacao.xls>. Acesso em: 18 abr. 2009.

FURLANI, C.E.A.; JÚNIOR, A.P.; LOPES, A.; SILVA, R.P.; GROTTA, D.C.C.; CORTEZ, J.W. Desempenho operacional de semeadora-adubadora em diferentes manejos da cobertura e da velocidade. Engenharia Agrícola, Jaboticabal, v.27, n.2, p.456-462, 2007.

GARCIA, L.C.; JASPER, R.; JASPER, M.; FORNARI, A.J.; BLUM, J. Influência da velocidade de deslocamento na semeadura do milho. Engenharia Agrícola, Jaboticabal, v.26, p.520-527, 2006.

IAPAR. Aveia-Preta IAPAR 61 Ibiporã, 2011. Disponível em: <http://www.iapar.br/arquivos/ File/zip_pdf/aveia-preta.pdf>. Acesso em: $1^{\underline{0}}$ ago. 2011.

KRANZ, J. Measuring plant disease. In: KRANZ, J.; ROTEM, J. (Ed.). Experimental techniques in plant disease epidemiology. Heidelberg: Springer, 1988. p.35-50.

MAGALHÃES, P.C.; DURÃES, F.O.M. Fisiologia da produção. In: CRUZ, J.C.; KARAM, D.; MONTEIRO, M.A.R.; MAGALHÃES, P.C. A cultura do milho. Brasília: Embrapa Informação Tecnológica, 2008. v.1, p.64-87.

NOVAIS, R. F.; MELLO, J.W.V. Relação solo-planta. In: NOVAIS, R.F.; VENEGAS, V.H.A.; BARROS, N.F.; FONTES, R.L.F.; CANTARUTTI, R.B.; NEVES, J.C.L. Fertilidade do solo. Viçosa: Sociedade Brasileira de Ciência do Solo, 2007, v.1, p.133-204.

REINERT, D.J.; ALBUQUERQUE, J.A.; REICHERT, J.M.; AITA, C.; ANDRADA, M.M.C. Limites críticos de densidade do solo para o crescimento de raízes de plantas de cobertura em Argissolo Vermelho. Revista Brasileira de Ciência do Solo, Viçosa-MG, v.32, n.5, p.1.805-1.816, 2008.

ROSOLEM, C.A.; CALONEGO, J.C.; FOLONI, J.S.S.; GARCIA, R.A. Potássio lixiviado da palha de aveia-preta e milheto após a dessecação química. Pesquisa Agropecuária Brasileira, Brasília, v.42, n.8, p.1.169-1.175, 2007.

SANTOS, A.J.M.; GAMERO, C.A.; BACKES, C.; SALOMÃO, L.C.; BICUDO, S.J. Desempenho de discos de corte de semeadora-adubadora em diferentes quantidades de cobertura vegetal. Revista Energia na Agricultura, Botucatu, v.5, n.4, p.17-30, 2010. 